\title{
Focalización cero en La ciudad y los perros: simulación sincrónica de protagonismo autónomo
}

\author{
Zero Focus on The Time of the Hero: Synchronous Simulation of Autonomous \\ Protagonism
}

Jesús Miguel Delgado Del Aguila

UNIVERSIDAD NACIONAL MAYOR DE SAN MARCOS

ORCID: http://orcid.org/0000-0002-2633-8101

RESUMEN: La ciudad y los perros (1963) desarrolla una historia de vivencias adolescentes que ocurre mayormente en el Colegio Militar Leoncio Prado. Resulta de interés apreciar cómo se abordó esa convivencia, caracterizada por la frecuencia de la violencia y los constantes disturbios internos de los cadetes. Sobre este tópico, la crítica literaria ha realizado diversidad de estudios, que han sido de utilidad para comprender la composición técnica y temática de la obra. Ante ello, existe un tratado que deseo fluctuar, que se basa en el efecto que genera la estrategia narrativa de la focalización cero. Es importante el entendimiento de ese recurso para explicar cómo se produce la confusión sincrónica al querer reconocer los enunciados y las acciones de los personajes que se muestran con una ambigüedad premeditada. En ese sentido, este artículo tendrá por objetivo detectar cuáles son esas semejanzas y esas diferencias que dificultan provisionalmente la identificación correcta de los protagonistas.

Palabras clave: focalización cero, autonomía, autoría, confusión, lectura.

ABSTRACT: The Time of the Hero (1963) develops a history of adolescent experiences that takes place mainly in the Leoncio Prado Military Academy. It is interesting to appreciate how this coexistence was approached, characterized by the frequency of violence and the constant internal disturbances of the cadets. On this topic, literary criticism has carried out a variety of studies, which have been useful to understand the technical and thematic composition of the work. Given this, there is a treaty that I want to fluctuate, which is based on the effect generated by the narrative strategy of zero targeting. The understanding of this 
resource is important to explain how synchronic confusion occurs when wanting to recognize the statements and actions of the characters that are shown with a premeditated ambiguity. In this sense, this article will aim to detect which are those similarities and those differences that provisionally hinder the correct identification of the protagonists.

Key words: zero focus, autonomy, authorship, confusion, reading.

\section{INTRODUCCIÓN}

En La ciudad y los perros ${ }^{1}$, el lector percibe que el Jaguar, el Poeta y el Esclavo coinciden con patrones que se han desarrollado con profesionalismo en la novela. Un ejemplo inminente de este caso es cuando los tres interactúan con Teresa, sin que exista ni una sospecha de que se trate de cualquiera de ellos. Es más, se asume por un tiempo que no existe esa división de autoría en sus participaciones. No obstante, se va descubriendo en el transcurso de la historia que se trata de personajes distintos, a los que he denominado protagonistas. Por otro lado, se genera una atmósfera de paralelismo en sus acciones y sus monólogos, pese a las diferencias del tiempo y la narración de todo el texto. Considerando esas divergencias, propongo el objetivo de mi artículo. Este se ceñirá a indagar sobre la temática de la intrincación para identificar al Jaguar, Alberto Fernández y Ricardo Arana. Para demostrar esa hipótesis, hago referencia a la disposición del narrador en atribuir caracteres similares a los personajes. Este es el motivo esencial por el cual se acarrea un falso reconocimiento.

Este tipo de trabajo se examinó previamente desde dos modalidades hermenéuticas. La primera justifica el estilo del autor. Él habría hecho esa estrategia deliberadamente para ocasionar esa sensación de confusión protagónica durante la lectura. Esta postura la ha desarrollado Joseph Sommers (1975), Joel Hancock (1975), Donald Shaw (1999), Néstor Tenorio (2011) y David Sobrevilla (2011). La segunda variante fue formulada por José Miguel Oviedo (1981), Antonio Cornejo Polar (1982), Brigitte König (2001) y Carlos Garayar (2012). Ellos postularon que la volición de Vargas Llosa consistió en velar la complexión de los personajes. Con estos dos argumentos, es conveniente conceptualizar la categoría del narrador para que los ejemplos resulten más comprensibles. Encima, será de utilidad profundizar sobre las formas con las que se presentan los personajes y cómo suscitan esa intervención inextricable.

Normalmente, se entiende por narrador a quien tiene la potestad para organizar la enunciación del discurso. A su vez, administra el espacio, el tiempo y los personajes que deben plasmarse en una obra. Para Walter Benjamín (2001), se trata de quien manipula toda esa información desde su propia libertad creativa. Esas pautas son necesarias para determinar la manera de producir la intrincación protagónica en La ciudad y los perros; es decir, residiría en una actitud del escritor. Esa modalidad subyace a una tipología. Esta serviría para entender la dinámica de exposición y ocultamiento de los personajes. Cuando se opta por proyectar al narrador en el texto, se recurre a uno homodiegético. Este contará desde la $1 .^{\mathrm{a}}$ persona. Sin embargo, también se podrá usar el narrador heterodiegético, quien relata desde la 3. ${ }^{\mathrm{a}}$ persona. Existen otras viradas, como la del autor narrador o el de la focalización cero. Este último es conocido como el de narradores

\footnotetext{
${ }^{1}$ La edición de La ciudad y los perros que se está empleando para esta investigación es la que le pertenece a la Real Academia Española (2012). Utilizaré este texto como referencia para incorporar algunos ejemplos que se relacionan con la parte teórica-interpretativa del artículo.
} 
múltiples o multiperspectivas ${ }^{2}$. Se distinguirá por generar una sensación de invisibilidad desde el discurso. Así, se aprecian las variantes con las que se muestra al narrador. Si se procura su encubrimiento, se acotará la complicada identidad de los protagonistas. Ellos deberán exhibirse desde su caracterización coincidente y colectiva. Esa será la única manera para poder integrarlos en un plano en el que la confusión por concernirlos sea posible. En este caso, la teoría de Alain Badiou (2003) facilita que se detecten los patrones que forman parte de la complexión de un personaje. A su vez, se asumirá que estos elementos pertenecen a un conjunto reconocible y natural de una etapa de la vida. Así, se adoptaría una errónea auscultación, que sería esclarecida más adelante. Ese descubrimiento se hará al cotejar con los talantes que no concuerdan.

Previo a este estudio, se encuentra el texto La narrativa totalizadora de José María Arguedas, Julio Ramón Ribeyro y Mario Vargas Llosa (2001), en el que el autor Carlos Schwalb considera que existe un proyecto totalizador en la narrativa de los sesenta que comprende la complejidad y la pretensión de abarcar la realidad absoluta. Esa configuración idónea originaría la percepción de lo caótico y lo desordenado que resulta el ser humano desde los lineamientos que le impone la sociedad. Esta teoría sirve para elucidar una taxonomía de los estratos sociales. Para La ciudad y los perros, se trata de confrontar con los universos de la educación militarizada, los niveles socioeconómicos de los cadetes y la calle. No obstante, la focalización cero impide la distinción de un personaje en un espacio en concreto. Solo unifica todas las conciencias expuestas en el libro, para presentar lo complicado y lo convulso de la búsqueda de una identidad. Una apreciación afín se halla con el aporte de Rosa Boldori (1966). Su discernimiento se puede sintetizar de la siguiente manera: «La postulación esencial de la novela, en el plano de la fundamentación ideológica, consiste en la imposibilidad del hombre de superar los condicionamientos del medio social y geográfico, en su determinismo ambiental» (1966: 92). Con esa propuesta, se constata una subordinación y una resignación al tipo de vida que se desarrolla en la institución. Eso explicaría que los alumnos estén sometidos a un determinismo ambiental (Boldori, 1966: 93). Sin embargo, queda inconcluso qué es lo que impulsa a la elección de ese estilo de vida, además de que no se reconocen cuáles son las identidades sincrónicas que van asumiendo los personajes. Un estudio teórico sobre el estilo del autor permitiría dilucidar cómo se van articulando los rasgos comunes que se atribuyen al Jaguar, el Poeta y el Esclavo.

\section{EL TIEMPO Y LA NARRACIÓN: CONFUSIÓN PROTAGÓNICA MOMENTÁNEA}

La crítica literaria ha abordado las temáticas del tiempo y la narración desde dos perspectivas. Una de ellas se basa en el trabajo estilístico del escritor. Y la otra se enfoca en el ocultamiento de la complexión de los personajes principales.

La primera orientación ha sido planteada por Joseph Sommers (1975), Joel Hancock (1975), Donald Shaw (1999), David Sobrevilla (2011) y Néstor Tenorio (2011). Ellos parten de la noción de que no predomina la descripción endógena de los personajes, sino las diversas técnicas empleadas por el novelista, como los múltiples puntos de vista.

\footnotetext{
${ }^{2} \mathrm{Al}$ retomar la focalización cero, el autor revela la influencia que adopta de William Faulkner. Al confrontar con esa técnica, se administran las conciencias que se plasman en el relato. Genera un efecto psicológico de similitud, paralelismo, multiplicidad o confusión de voces. Este se logrará si se hace una buena labor en la composición verbal; es decir, en lo dialógico y lo polifónico. De ser así, un monólogo producirá esa sensación al someterse a cualquier otro artificio, como el de los saltos temporales. Para finalizar, este escritor norteamericano no solo se ha caracterizado por su idónea distribución de estrategias narrativas, sino que también se le reconoce su función de criticar las bases de lo sociológico y lo histórico.
} 
Estos tienen el propósito de retratar la realidad externa. Y se presentan con alternancia y contraste de personajes, tiempos y espacios. De todos esos elementos, Sobrevilla (2011) se refiere al monólogo interior ${ }^{3}$; en rigor, cuando lo usa el Boa. En la obra, el tratamiento del personaje con ese recurso impediría conocer su intimidad. Esa sensación de curiosidad será perenne en el autor. De allí, se preocupará en desarrollar esa técnica novelística con mayor destreza, que posee el rol de representar lo subjetivo de la realidad. La misma función tienen los vasos comunicantes, las cajas chinas y la muda o el salto cualitativo. $\mathrm{Su}$ valor es estilístico. Estos suscitan un efecto de simultaneidad rítmica, en concordancia con las historias que se vinculan entre sí en un punto determinado. Optar por esos mecanismos complejos es asequible para configurar un universo más amplio que integra distintas realidades estructurales que se aprecian en los intereses de Vargas Llosa. Para Joseph Sommers (1975), este recurso del autor es una manera de unificar la visión del mundo con la del texto. Él se basaría en la denuncia social y la existencia arquetípica, ya que de estas sobresale la percepción negativa y deshumanizadora que caracteriza a la novela. Serán comunes sus imágenes constantes y excesivas que establecen igualdades entre el comportamiento animal y el antropológico. Pese a ello, otra es la interpretación que brinda José Miguel Oviedo (2012). Él se estriba en que esas relaciones abrumadoras se justifican por la ignorancia de los estudiantes sobre la supervivencia adecuada en ese ambiente castrense. Es decir, su reacción violenta y anómala es una evasiva inconsciente a esa realidad tormentosa, en la que no solo prevalece esa maldad involuntaria, sino un apego emocional y una concientización básica. Esto se manifiesta en la postura que adopta el exégeta con respecto a la trabazón entre el Boa y la perra Malpapeada, tal como se evidencia a continuación: «Este lenguaje tronchado, irracional, incoherente, llega a traslucir, en otros momentos, una ruda ternura, una poesía áspera que recuerda al Vallejo de Trilce» (Oviedo, 2012: LIII). Incluso, le atribuirá unos valores ambivalentes al sentimiento que se produce en el muchacho. Estos se conformarán por el amor-odio, el odio-cariño, lo nefasto-patético y lo abismal-orgánico.

La segunda orientación consiste en el encubrimiento de la identidad de los personajes. Allí se encuentran los planteamientos de José Miguel Oviedo (1981), Antonio Cornejo Polar (1982), Brigitte König (2001) y Carlos Garayar (2012). Según estos críticos literarios, el trabajo estilístico de Vargas Llosa recibió influencia de la narrativa norteamericana; en especial, la de William Faulkner ${ }^{4}$. Asimismo, se hace mención de su adscripción a la generación del 50. Todas estas filiaciones concuerdan en intentar fundamentar esa solvencia creativa del narrador, quien plasma sus relatos con autonomía. Acerca de ello, Antonio Cornejo Polar (1982) sostiene que su obra era más arte de composición que de narración, debido a su uso pulcro del orden. No obstante, no solo se refiere a un artificio para el autor, sino que él asume la escritura como ejercicio de epifanía y denuncia a la realidad social. Su lenguaje juzga y revela la condición humana. Además, se empeñará por mostrar su discurso desde otra perspectiva. La presentación de los elementos se someterá a una dinámica de exposición y ocultamiento de información. Eso explica por qué prevalecen nombres, deícticos y vocativos que de inmediato delatan la autoría individual y personificada de los monólogos elaborados. Sin embargo, no siempre se recurrirá a esa forma rápida de exhibir a los personajes. Se opta por la invisibilidad, la

\footnotetext{
${ }^{3}$ Para Rosa Boldori (1966), el monólogo interior sería uno de los mejores aportes de la narrativa de Mario Vargas Llosa.

${ }^{4}$ La influencia de William Faulkner se aprecia en la nueva orientación que el autor otorga a los personajes antagónicos, como al mostrarlos como prototipos humanos. Esa cualidad se corrobora con el Jaguar, quien es un símbolo de la persistencia y la inconformidad. Al respecto, Mary Davis (1982) hizo referencia a la idea del fracaso que adopta Mario Vargas Llosa en su novela; más bien, esta se desvirtuaría al provocar un efecto contrario. Se trataría de una oportunidad para demostrar un grado álgido de moralidad y superación personal.
} 
dualidad y la imparcialidad para originar contrastes y desajustes en el tratamiento de la novela y los personajes, así como para reforzar la impresión de soledad y violencia. También, se hallan las técnicas cinematográficas, como el montaje (Oviedo, 1981: 193). $\mathrm{Su}$ inclusión demuestra el estilo del autor. Una vez que se logra la comprensión cabal y una aproximación a la verdad de los sucesos se consigue el propósito primordial. Entre otros aportes teóricos relacionados con el escritor peruano, se encuentra el que trabaja Ewa Kobylecka en El tiempo en la novelística de Mario Vargas Llosa (2010). De su estudio, es neurálgico recapitular tres conceptos innovadores que se asocian con la focalización cero. El primero que postula es el de relato con una distancia temporal nula (Kobylecka, 2010: 98-123). Este se basa en la invisibilidad del narrador en el texto, por lo que será imposible introducirlo en el mismo plano de los personajes. El segundo término que sustenta Kobylecka (2010) es el relato con una distancia temporal marcada. En este, se evidencia una congruencia entre el que cuenta y el que actúa. Su avance en la trama demostrará que evoluciona y adopta otros comportamientos según las exigencias. Esas modificaciones serán justificadas, por lo que no supone una tergiversación para su entendimiento. Y la última categoría es la del relato con una distancia temporal cero (Kobylecka, 2010: 142-166). Esta se distingue por limitar la intervención del narrador personaje en un tiempo reducido, tanto así que se inmiscuye en el monólogo interior. Encima, se hallan los elementos del género policial (Tenorio, 2011: 95). Con estos, la investigación sobre el asesinato y las acciones que se desenvuelven resultan verosímiles. Esta será uno de los recursos que desentrañan la adscripción de Vargas Llosa a la novelística de William Faulkner. Por otro lado, se considera la familia lingüística (Forgues, 2001: 445), a causa de que los personajes no poseen ni dominan un habla homogénea. El autor se adapta a cada circunstancia para no provocar la ambigüedad.

Ante la disposición del tiempo y la narración que utiliza el autor, expondré la teoría en torno a los estilos que se requieren para producir la confusión sincrónica en el lector con respecto a la complexión de los protagonistas. Para ello, desarrollaré la epistemología del narrador y sus derivados.

\subsection{EL NARRADOR}

Es el sujeto de la enunciación del discurso; es decir, se encarga de organizar las instancias discursivas, como el distanciamiento que existe entre él y sus personajes. Él partirá de esa modalidad, que se constituye por la deixis yo-aquí-ahora (Blanco, 2009: 58). Desde allí, planificará y autentificará los mundos insertados en su creación artística, además de emplear correctamente las técnicas literarias. También, usará con pertinencia el tono y los ritmos. Para Walter Benjamín (2001), la experiencia que vaya adquiriendo será esencial para forjar la capacidad intelectual del narrador. Sus conocimientos deberán acoplarse al gusto del receptor, sin descuidar la forma en la que plasmará su discurso. El tratamiento puede ser entendible o complejo. Está apto para manipular los espacios que representa para orientarlos a oposiciones relativas. Lo mismo hará con las perspectivas, las distancias y los acercamientos. Si desea, alterará la secuencia de la historia: se adelantará a los hechos, evocará el pasado o evitará el futuro. Con esos artificios, se conseguirá un abordaje más amplio, que permitirá que el lector se cerciore de detalles, planos generales y específicos. Todo ello tendrá un fin estético.

\subsubsection{Las formas del narrador}


El narrador puede mostrarse de diversas maneras. Optará por ser homodiegético, heterodiegético, autor narrador o asumirá la focalización cero ${ }^{5}$.

Para empezar, el narrador homodiegético también es denominado como intradiegético. Este se desarrollará cuando el relato sea individual o en $1 .^{a}$ persona. Adoptará una condición más subjetiva y se implicará en lo más profundo del texto. Se inmiscuye en los pensamientos de los protagonistas y se limita a presentarlos desde la confesión. Esto se evidencia en un monólogo del Jaguar: «Iba a esperarla a la salida de su colegio dos o tres veces por semana, pero no siempre me acercaba» (Vargas Llosa, 2012: 234). Como se coteja del ejemplo anterior, prevalece un interés por resolver cuestiones íntimas, en vez de preocuparse por el avance común de la historia.

Segundo, el narrador heterodiegético o extradiegético cuenta sin involucrarse en la diégesis. Recurre a la $3 .^{\mathrm{a}}$ persona para construir imágenes, detalles físicos y sentimentales, sin interiorizar. Relata solo lo que transcurre. Es como un narrador cinematográfico, ya que manipula datos para expresarlos con objetividad, rapidez y suspicacia. Para Enrique Páez (2001), se trata de un narrador omnipresente, debido a que lo sabe todo. Esa peculiaridad le permitirá que sus producciones generen interpretaciones abundantes de lectura. Eso es notorio en una descripción como la siguiente: «Había una luz blanca y penetrante que parecía brotar de los techos de las casas y elevarse verticalmente hacia el cielo sin nubes» (Vargas Llosa, 2012: 447). En ese fragmento, se corroboran elementos de la naturaleza que son expuestos con una volición. Indagar en torno a ello provocará el conocimiento de una atmósfera de la novela.

Tercero, existe una intervención en 3. a persona en el caso del autor narrador. Se hace de tal manera que se combina con los narradores personajes que alternan entre la $3 .^{\mathrm{a}}$ y la 1. a persona. Eso anula la distancia entre narrador-lector y se va inscribiendo en una categoría antropológica denominada homo faber. Esta consiste en la naturaleza humana para fabricar la obra. Bajtín (1991) añade que el autor-creador tiene libertad para manejar el tiempo que le designa a su invención. Puede comenzar su discurso por el final, la mitad o cualquier momento que considere pertinente. Todo eso lo hace sin transgredir el decurso fehaciente del tiempo. En La ciudad y los perros, se aprecia este tipo de narrador al encontrarse las focalizaciones diversas de los personajes.

Cuarto, la focalización cero es palmaria cuando hay bastantes narradores o multiperspectivas. Se alternan la $1 .^{\mathrm{a}}$ y la $3 .^{\mathrm{a}}$ persona del singular. Su modo de relatar se distingue por la omnisciencia del novelista clásico y la intención implícita de eliminar las huellas del autor. Su propósito es comparar la narración con una mente unificadora o un conjunto de voces. Eso origina que los protagonistas se intercalen y se asuman enfoques heteróclitos sobre ellos. Verbigracia, el Jaguar es violento y criminal. El Poeta sabe adaptarse a las situaciones. Y el Esclavo es una víctima de ese sistema caótico. Esos virajes impiden que se consolide un interés propio de la novela realista, que pretende homogeneizar todos los eventos que se presentan (Auerbach, 1996: 514-515). Así, se percibe la naturaleza pluripersonal, que incluye conciencias inusitadas y mundos afines, sin descuidar su carácter auténtico. Una óptima representación polifónica tendrá que asegurar la autonomía del uso verbal de cada uno. En cambio, la focalización cero fallará si los personajes empiezan a petrificarse o cosificarse. Por ese motivo, la actividad polifónica deberá ser siempre dialógicamente activa, con renovación y diferencias del habla de cada uno.

El Poeta, el Esclavo y el Jaguar son casos concretos de cómo la focalización cero se ha establecido en la novela de forma independiente. Para generar la confusión, se redacta en $1 .^{\mathrm{a}}$ y $3 .^{\mathrm{a}}$ persona. Se narra desde la primera modalidad con un monólogo

\footnotetext{
${ }^{5}$ Efraín Kristal (1999) hace un estudio del tipo de narradores que se usa para relatar las historias de los cadetes. Además, destaca el tiempo pretérito que se emplea para cada intervención.
} 
homodiegético, tal como se muestra en un pensamiento de Alberto Fernández: «Y le escribí una y otra y la chica me contestaba y el cuartelero me convidaba cigarros y colas en La Perlita» (Vargas Llosa, 2012: 169). En ese ejemplo, se relata desde un "yo" para revelar las acciones que se ejecutan en un tiempo pretérito. Otro es el desenvolvimiento al emplear el narrador heterodiegético, tal como se atisba a continuación: «Alberto camina por las serenas calles de Barranco, entre casonas descoloridas de principios de siglo, separadas de la calle por jardines profundos. Los árboles, altos y frondosos, proyectan en el pavimento sombras que parecen arañas» (Vargas Llosa, 2012: 325). Allí, se manifiesta la identidad del personaje para ubicarlo en un lugar específico en un tiempo presente.

Ocurre lo mismo con Ricardo Arana, quien se plasma en $1 .^{a}$ y $3 .{ }^{a}$ persona. Para el caso inicial, se aprecia su divagación particular: «Estaré seis horas en la calle. Iré a verla pero no podré decirle nada de lo que ha pasado» (Vargas Llosa, 2012: 159-160). En esta oportunidad, es perentoria una visión orientada al futuro de lo que el personaje desea realizar. Para el segundo caso, se hallan diversas alusiones por el narrador hacia el protagonista, como en este fragmento: «El Esclavo se levanta como un resorte, pero permanece en el sitio sin dar un paso, como pendiente de algo próximo e irremediable» (Vargas Llosa, 2012: 28). Allí, se recurre al tiempo presente para explicar su desempeño en un espacio habitual.

Sucede igual con el Jaguar. Su focalización se efectúa desde la $1 .{ }^{a}$ persona. Y se atisba en la siguiente ocasión: «Yo estaba en el Sáenz Peña y a la salida volvía a Bellavista caminando. A veces me encontraba con Higueras, un amigo de mi hermano, antes que a Perico lo metieran al Ejército» (Vargas Llosa, 2012: 73). Es posible reconocer al enunciador desde un «yo» en un tiempo pretérito, aunque muchas veces se omite su apodo. Por otro lado, se evidencia desde la $3 .{ }^{\text {a }}$ persona, tal como acontece a continuación: «El Jaguar estaba de pie y describía a un cadete de cuarto, un brigadier. Los demás lo escuchaban en cuclillas, como de costumbre; las colillas pasaban de mano en mano»» (Vargas Llosa, 2012: 66-67). Al formularlo de ese modo, no incita a la confusión, porque se ubica al personaje en el hábitat en el que el lector se acostumbra a localizarlo. El problema surgirá con los monólogos que se desarrollan fuera de ese entorno, ya que ni se expresa que él sea quien intervenga.

En suma, es común comprobar que con la focalización cero se origina una crisis consciente en la representación. La identificación individual no ocurrirá de inmediato. Tendrá que existir una formación previa del lector para poder comprender las estrategias usadas, merced a que confunde la manifestación análoga de monólogos con eventos e intereses similares. Este argumento sobre la multiperspectiva ya lo había propuesto José Luis Martín en su libro La narrativa de Vargas Llosa: acercamiento estilístico (1974). En el texto, planteaba que la exposición de los cadetes del Colegio Militar Leoncio Prado era producto de la incongruencia de los valores que se fomentaban en el universo castrense y el ámbito social (Martín, 1974: 92). No prevalece una preocupación por forjar su identidad, sino de que concluyan su instrucción académica, sin importar cómo. Esa forma polémica de percibir el reclutamiento de los estudiantes termina siendo una crítica al militarismo (Martín, 1974: 44).

\subsubsection{El narrador y la confusión protagónica generada}

El narrador es quien configura el relato a su disposición. Su buen manejo de las técnicas literarias lo favorecerá. Eso es lo que pasa al saber emplear una estrategia discursiva que concreta su objetivo en La ciudad y los perros, como el de la focalización cero. Esta tiene la finalidad de inducir a una intrincación provisional para el reconocimiento de los protagonistas. Para poder desarrollar esa táctica, me referiré a cinco 
tópicos que explicarán la manera como se irá desentrañando la complexión de los personajes: por su caracterización individual, la relación del ser con la multiplicidad, la confusión provocada en la auscultación, el cuestionamiento de la verdad por parte del lector y la revelación de las identidades.

Primero, la caracterización individual es uno de los elementos que originan una confusión sincrónica, propia de la focalización cero. Esta constitución autónoma se vale de los atributos que se van brindando de los mismos discursos, como los temas consuetudinarios que aluden a su comportamiento, sus manías y sus cualidades. Con ello, se devela el interés del autor en proporcionar una mayor catálisis y una mejor dedicación en la forma de presentación. Estas normas que contribuyen a la unidad se hacen propicias en la separación y la apropiación de experiencias temporales de ficción que vive cada personaje. Verbigracia, uno de rol pasivo no tendrá una vida caracterizada por la agresividad. Él no será el principal incentivo de ese tipo de desorganizaciones. No obstante, esa condición violenta sí será asumida por otro personaje de naturaleza pleitista. Las experiencias negativas se adaptarán a su conducta humana, pero no resultará del todo genérico. Cada uno será representado por un narrador en $3 .^{\mathrm{a}}$ persona, a través de diálogos o acciones. Para el caso de la novela, es neurálgico acotar la historia de cómo suscita el apodo del Jaguar. Su complexión se irá consolidando desde los actos violentos que ha realizado como sublevación contra los cadetes superiores.

Segundo, referirse a uno del múltiple facilita que se aluda a la intención de la focalización cero. Su incorporación desde esa perspectiva permite diferenciar el rol del violento en la sociedad. Esa disposición se efectúa por lo que plantea Alain Badiou (2003) al sostener que la representación del ser se debe a que ya existe algo preconfigurado del cual se toma referencia. En esta ocasión, se conoce cómo es una actitud violenta y se sabe que se parte de una realidad verosímil. Los integrantes pueden ser presentables desde esos lineamientos. Así, exponer a una comunidad agresiva o uno de los que la conforman será pertinente. Su reconocimiento será inmediato. Tampoco se cometerá el error de insertar a entidades que se desliguen de esa complexión. Para que esa identificación sea adecuada, tendrán que cumplirse ciertos requisitos. Desde el concepto operativo de Badiou (2003) del cuenta-por-uno, es posible adaptar los patrones iterativos de la violencia y verificar si son repetitivos en un conjunto. De ser exitosa la comprobación, se podrá aludir a una exposición heterogénea y reincidente. Por ejemplo, un entorno social violento supone que los integrantes posean una constante agresiva, como la del lenguaje ofensivo. Por lo tanto, es factible extraer una entidad autorregulada de esa representación diversa. Un sujeto se habrá erigido desde ese grupo social al acatar esas condiciones. La ciudad y los perros muestra un centro educativo estribado en un orden militar agresivo. Su epifanía funciona como contraparte a lo que se aprecia en la sociedad peruana. Los alumnos del Colegio Militar adoptarán una disciplina autoritaria y violenta. Eso explica por qué el Jaguar, el Boa, el Poeta, el serrano Cava, el negro Vallano, el brigadier Arróspide y hasta el Esclavo cuentan con características similares. El último de ellos no manifiesta ninguna de estas actitudes agresivas, aunque sí las tiene reservadas. Si se considera al Jaguar, resulta ser un personaje violento destacable entre los otros cadetes. Además, se incluye en una colectividad criminal, donde se encuentra el flaco Higueras, que ha sido adiestrado en la calle. No es el más agresivo en ese ámbito. Se comportará así en su institución y se diferenciará del resto.

Tercero, la focalización cero provoca la intrincación de los personajes por sus semejanzas. Ellos se irán complejizando al desarrollarse más la trama de la novela. Su forma endógena se empezará a reconocer por sus conflictos internos y sus tranquilidades. No obstante, ¿a qué se debe que exista equidad en sus monólogos, si se sabe que el lector disociará sus distintos perfiles? Esto sucede cuando se concuerda con su propia 
naturaleza, y se acepta. La congruencia se habrá originado por el hallazgo y el tratamiento de una iterativa acumulación de patrones autónomos, como su violencia palmaria, el tránsito de la misma etapa de vida y las interrelaciones sociales con personajes y situaciones análogas. En consecuencia, se logra una inmersión equívoca e irrefutable para el lector. Si se presenta un monólogo con los talantes anteriores, se asume que quien interviene es el Poeta. La falta de marcas deícticas y vocativos que aludan al Jaguar interferirán en su auscultación. Se designará una autoría inconclusa. Esa confusión también se apreciará al mostrarse espacios heterogéneos de desenvolvimiento para los protagonistas. Ellos fraguarán en determinados contextos de Lima y revelarán una reciprocidad inherente y compatible. Sin embargo, ese problema se irá resolviendo al finiquitar la historia del libro. Se terminará comprendiendo que tampoco no consiste en una desintegración de la personalidad. Con respecto a La ciudad y los perros, la semejanza errónea se establecerá en los monólogos que carecen de enunciador explícito. Esto acontece con las narraciones remotas e individualizadas desde la 1. ${ }^{a}$ persona; sobre todo, cuando se propone a los muchachos ser matriculados en la institución castrense. Al no encontrarse marcas de propiedad enunciativa, es convincente que se trate del Poeta, el Esclavo o el Jaguar. Por el contrario, esa auscultación equívoca solo se producirá en la lectura parcial de la novela; es decir, mientras que se ignore la última conversación del Jaguar con el flaco Higueras. Algo similar se corrobora en la uniformidad de atributos en los protagonistas. Esta se evidencia mediante el conocimiento que poseen Ricardo Arana y Alberto Fernández de Teresa, mas el Jaguar queda distanciado de ello, durante el progreso de la narración. No se indica literalmente que él la frecuente. Esto acaece al final de La ciudad y los perros (1963). Allí se desentraña que fue su pretendiente. Esto genera que se sepan las múltiples identidades que se plasmaron en el texto, que no se refieren tan solo al Poeta. Acerca de esto, mencionaré dos situaciones de ocultamiento del autor de los monólogos. En estos, el Jaguar involucra al flaco Higueras y Teresa desde el anonimato.

Una vez pensé: «Nunca he estado a solas con ella. ¿Y si fuera a esperarla a la salida de su colegio?». Pero no me animaba. ¿Qué le iba a decir? ¿Y de dónde sacaría dinero para el pasaje? [...]. Hasta que un día se me ocurrió pedirle prestado un sol al flaco Higueras [...]. Apenas hablamos en el camino. Ella contestaba a todo lo que yo decía, pero sin mirarme. Cuando llegamos a una esquina, me dijo: «Mis tíos viven en la otra cuadra, así que mejor me acompañas solo hasta aquí»».

(Vargas Llosa, 2012: 131-133)

El segundo ejemplo se desarrolla desde la misma perspectiva y con los personajes aludidos con anterioridad.

La primera vez fuimos a La Perla. El flaco Higueras me preguntó si no me importaba caminar o si quería tomar el ómnibus [...]. A ratos me olvidaba que estaba allí y me parecía que todo era un sueño y que estaba en mi cama y se me aparecía la cara de Tere y me venían unas ganas de verla y de hablarle [...]. Yo le dije: «Los he comprado para regalártelos». Y ella me dijo: «¿De veras?». «Claro», le contesté. «Tómalos».

(Vargas Llosa, 2012: 316-320)

En estos casos, se aprecia algo recalcitrante: el narrador no alude a las identidades articuladas ni tampoco los personajes delatan su referencialidad. Al respecto, Ewa Kobylecka (2001) sostiene que este artificio de exponer conversaciones en tiempos disímiles es propio de la técnica de los diálogos telescópicos o las cajas chinas. Lo particular en esa estrategia discursiva será que se generan otras historias. Esa configuración será permutable, ya que en otras ocasiones se exhibirán situaciones distintas en las que se revela al Jaguar por medio del uso de vocativos. Estos se 
exteriorizarán en los diálogos en $2 .^{\mathrm{a}}$ persona del singular. No obstante, esta alternancia se evidencia en una dinámica que refuerza el encubrimiento.

Cuarto, se cuestiona la veracidad con la introducción de la focalización cero. Surge esa necesidad de reconocimiento ante la disgregación, la uniformización y la simplificación. Esa pulsión se comprende por lo que Mario Perniola (2008) denomina como estética de la vida, una creencia que se abarca para aproximarse a la fidelidad de los hechos. Ese proceso ocurre en la religión y la historia de la Iglesia, a expensas de que suceda algo insólito que se claudique de los disturbios de la realidad. Por el contrario, ese empecinamiento es absurdo para Alain Badiou (2003). Será una ilusión, puesto que la realidad no es única, ni autónoma ni estática por más elementos modernos que se le incorporen. Ese todo siempre será inaccesible. Por esa razón, lo único finito y certero es el resultado postremo, como al aludir a que el ser existe en tanto múltiple compuesto y que se encuentra tan solo destinado para la muerte. Por ello, es impreciso otorgar una respuesta auténtica en momentos específicos de La ciudad y los perros. El lector no puede inferir con rapidez quién mató al Esclavo o quién robó el examen de Química. También desconocerá qué personaje se está abordando desde los monólogos de la novela. Podría ser el Poeta, el Jaguar o el Esclavo. Entonces, si se presentan confusiones, lo más recomendable es que estas se muestren paulatinamente o que se postule una explicación provisional que las justifique. En ese caso, es útil respaldarse de lo que formula Umberto Eco: «El ser es tal que de él se pueden dar diferentes interpretaciones» (1999: 45). Esa sensación de pluralidad anulará las ansias por considerar el texto como un material contundente e inmutable.

Quinto, se desentrañan identidades distintas con el uso de la focalización cero. Sobre ello, el lector se va enterando de esa situación conforme transcurre la historia. Al final de la obra literaria, se percata de que la epifanía de los protagonistas se condicionó a una convención de un múltiple consistente. Este significaría la alusión a una totalidad conflictiva y heterogénea que buscar enriquecer el concepto de hombre, en todos sus aspectos. Radicaría en un patrón reducible de la inmensa diversidad del universo. Sin embargo, es posible destacar que se ignora la verdadera intención si el objetivo se limita a esa elucidación. Es neurálgico deslindar la tensión efímera que se ha generado por la incertidumbre protagónica. Para lograr ese propósito, fue indispensable una buena labor con el lenguaje, el tiempo, las acciones similares y las interrelaciones reincidentes. Al finiquitar la novela, se claudican todos los elementos inservibles que se erigieron por error, como asumir que solo uno de los personajes es el autor de los múltiples monólogos. Esto ocurre en las últimas intervenciones del Poeta y el Jaguar, en las que se especifican su nexo con Teresa y la amistad exclusiva con el flaco Higueras (no con Alberto Fernández). Una vez que se revelan las identidades subrepticias, se muestran con exactitud el nombre y la autoría que rigen a cada protagonista. Además, se conoce que la narración estuvo sometida a un tiempo lúdico con personajes ininteligibles. No se precisó su identidad. Esa atmósfera absurda se desligó de la única red temporal y espacial de la realidad (Ricoeur, 1996: 818). No se trató de un tiempo cronológico. Con toda esa aclaración, el vínculo de personaje-acción queda plenamente evidenciado y garantizado. En consecuencia, se plasmarán la verdad y la funcionalidad de la técnica literaria de la focalización cero.

\section{CONCLUSIONES}

Este trabajo permitió condensar postulados de la exégesis literaria y la epistemología narrativa. Su objetivo fue abordar la focalización cero, que tuvo un 
tratamiento particular en este estudio. Los resultados que se obtuvieron de esta pesquisa se explicarán en los párrafos siguientes.

La crítica literaria se ha cerciorado de la volición de Mario Vargas Llosa en $L a$ ciudad y los peros (1963) al plantear que es notorio un universo fragmentado e impreciso. Para ello, fue importante destacar el libro de Carlos Schwalb (2001), en el que se fundamentó que el autor poseyó un proyecto totalizador al plasmar la realidad desde su desorganización innata. Esa condición sería indispensable para atribuirle un valor de verosimilitud al texto. Asimismo, esa configuración convulsa de la sociedad también fue confrontada por Rosa Boldori (1966), quien ratifica que los personajes se sometían a un contexto violento y castrense. Eso sería posible por el determinismo ambiental al que subyacían. Estos dos criterios sintetizan la propuesta panorámica del autor. Sin embargo, lo examinado por Joseph Sommers (1975), Donald Shaw (1999) y David Sobrevilla (2011) termina siendo más pormenorizado. Ellos se percataron de la confusión que acarreaba la lectura del libro al manifestarse diversas técnicas literarias. José Miguel Oviedo (1981), Antonio Cornejo Polar (1982), Brigitte König (2001) y Carlos Garayar (2012) efectuaron un trabajo mucho más contundente. Su formulación radica en desplegar la omisión de las identidades de los personajes. Entre otras investigaciones, se encontraron las realizadas por José Luis Martín (1974), Efraín Kristal (1999) y Ewa Kobylecka (2010), quienes abarcan la novela de Vargas Llosa, a partir de los recursos estilísticos empleados. La comprensión de estas estrategias discursivas generaría el desentrañamiento de la verdadera pretensión del autor. No obstante, no hubo un tratamiento directo que sustentara la intrincación que se podría eclosionar entre el Jaguar, el Poeta y el Esclavo, sin que se expusieran las razones. Todos estos temas se derivaron de un enfoque en concreto, mas no se hizo una relación inmediata con lo inextricable que concluye siendo su lectura.

Al tomarse en cuenta los estudios consumados, fue asequible elaborar un artículo que se diferenciara por su autonomía. Por el contrario, hubo algunas limitaciones para su avance consciente. En principio, fue por la actual trascendencia de las producciones artísticas del novelista peruano y su respectiva crítica a nivel mundial. Ese amplio repertorio discursivo impidió cotejar con el compendio de referentes afines; incluso, se eludieron aportes redactados en un idioma distinto del castellano. Encima, considerar todo lo que se ha comentado en torno a él resulta imposible, por lo que mi predilección por los estudios confrontados se ciñó a lo publicado desde ámbitos académicos. He obviado material periodístico, artículos de prensa, videoconferencias y documentos de acceso restringido. Por consiguiente, la elección de esta bibliografía no asegura que este trabajo parta de un conocimiento general de la abundante información que existe del autor.

Se demostró que la técnica literaria de la focalización cero se aplicó con la intención de que se plasmara un nuevo modo de narrar. Este claudicó del relato tradicional que sincronizaba con el tiempo y el espacio. Y destacó la libertad del narrador para disponer de los recursos concomitantes de un texto. Con ese artificio, la lectura de $L a$ ciudad y los perros se desligó de un procedimiento habitual y adoptó patrones inusitados. Estos se fueron evidenciando en el libro, a partir de talantes convenientes e incongruentes. Por ejemplo, se introdujeron monólogos que exhibían alternancias de situaciones y personajes, con el fin de emerger una percepción arbitraria al querer reconocer a su enunciador. Pudo tratarse del Jaguar, el Poeta y el Esclavo, pero se va revelando la individualidad de cada uno conforme se desarrolla la historia. Para esa ocasión, la operación teórica de cuenta-por-uno de Alain Badiou (2003) fue válida para diferenciar a cada protagonista. 
Con todo ello, es transigente afirmar el logro de esta pesquisa. Este consistió en la explicación teórica y estratificada de los elementos que intervinieron para suscitar un efecto de intrincación en la lectura. Por medio de esa argumentación, fueron notorios los límites que se establecieron al momento de configurar a un personaje. Una lectura parcial o incorrecta podría conllevar que se haga una identificación errónea. Para ello, fue infalible evocar la capacidad idónea del lector al confrontar con un texto de naturaleza compleja. También, se entendió que la complexión de personajes que se atraviesan por etapas semejantes provocará una distorsión en su auscultación. Esto se observa al referirse al tópico de los dobles, que ya ha sido abordado con protagonistas particulares de la literatura y el cine, como al aludir a gemelos, clones, pacientes con una enfermedad específica, tipo de criminales, alumnos de un mismo centro educativo o activistas de un partido político en concreto. En esas circunstancias, el narrador deberá tener la potestad para manejar esa atmósfera coincidente e informar con pertinencia sobre los hechos. Así, se cumplirá el efecto que anhela en su discurso, ya sea suspenso, terror, confusión o entretenimiento. En ese sentido, la multiperspectiva brindará la oportunidad de que se incorpore un enfoque intencionado en futuros trabajos de creación literaria. Ya se conoce cómo se va configurando esa expectativa, a partir de sus personajes. Y se sabe qué emerge en la lectura. Con respecto a la exégesis literaria, este artículo servirá para poder indagar acerca de los textos que omiten la autoría del enunciador o se presenta con difusión. De esa manera, se tomará en cuenta que existe un propósito del narrador en erigir una atmósfera enrevesada y subrepticia.

Una vez consolidadas las conclusiones, es neurálgico destacar qué podría estudiarse en La ciudad y los perros en un proyecto futuro. Por un lado, es factible que se examine cuál es la verdadera volición de cada estrategia discursiva empleada. En este caso, se sustentó que la focalización cero causaba intrincación y plasmaba componentes similares en los personajes. Eso se coligió desde la lógica de la novela. Su interpretación se justificó según la exposición del texto. Pero ¿eso ocurrirá en otros libros que han extrapolado este recurso estilístico? ¿Qué otras técnicas pueden generar confusión para la auscultación de identidades protagónicas? Ante estas interrogantes, es necesario recordar que esta investigación tuvo un tratamiento limitado de teóricos y críticos literarios. No se abarcó su totalidad, por lo que sería fructuoso complementar el panorama recabado. Es más, será de gran utilidad que se refuerce la construcción epistemológica, puesto que esta se consideró de forma metódica y objetiva. Queda pendiente que se realice ese recuento filológico sobre la multiperspectiva. Comprenderla a cabalidad originará nuevas interpretaciones en textos de condiciones uniformes.

\section{REFERENCIAS BIBLIOGRÁFICAS}

Auerbach, Erich. 1996. Mímesis. La representación de la realidad en la literatura occidental. Ciudad de México: Fondo de Cultura Económica.

Badiou, Alain. 2003. El ser y el acontecimiento. Traducción de Raúl Cerdeiras, Alejandro Cerletti y Nilda Prados. Buenos Aires: Manantial.

Bajtín, Mijaíl. 1991. Teoría y estética de la novela. Barcelona: Taurus Humanidades.

Benjamín, Walter. 2001. Para una crítica de la violencia y otros ensayos. Iluminaciones $I V$. Traducción de Roberto Blatt. Madrid: Taurus.

Blanco, Desiderio. 2009. Vigencia de la semiótica y otros ensayos. Lima: Fondo de Desarrollo Editorial, Universidad de Lima.

Boldori, R. 1966. «La ciudad y los perros, novela del determinismo ambiental». Revista Peruana de Cultura, (9-10): 92-113. 
Cornejo Polar, Antonio. 1982. Sobre literatura y crítica latinoamericanas. Caracas: Ediciones de la Facultad de Humanidades y Educación, Universidad Central de Venezuela.

Davis, Mary. 1982. «La elección del fracaso: Vargas Llosa y William Faulkner». En Mario Vargas Llosa, ed. José Miguel Oviedo. Madrid: Taurus, 35-46.

Delgado Del Aguila, Jesús Miguel. 2017. Protagonismo violento y modos de representación en La ciudad y los perros (1963). Tesis de licenciatura. Lima: Universidad Nacional Mayor de San Marcos.

Eco, Umberto. 1999. Kant y el ornitorrinco. Barcelona: Lumen.

Forgues, Roland. 2001. Mario Vargas Llosa: escritor, ensayista, ciudadano y político. Lima: Librería Editorial Minerva.

Garayar, Carlos. 2012. «La ciudad y los perros: la creación de un lector». En M. Vargas Llosa. La ciudad y los perros. Edición conmemorativa del cincuentenario. Italia: Alfaguara, Real Academia Española, 499-515.

Hancock, Joel. 1975. «Animalization and Chiaroscuro Techniques: Descriptive Language in La ciudad y los perros (The City and the Dogs)». Latin American Literary Review, 4 (7): 37-47.

Kobylecka, Ewa. 2010. El tiempo en la novelística de Mario Vargas Llosa. Vigo, España: Editorial Academia del Hispanismo.

König, Brigitte. 2001. «Metalingüística y oralidad fingida en Mario Vargas Llosa». En Mario Vargas Llosa: escritor, ensayista, ciudadano y político, ed. Roland Forgues. Lima: Librería Editorial Minerva, 443-463.

Kristal, Efraín. 1999. Temptation of the Word: The Novels of Mario Vargas Llosa. Nashville: Vanderbilt University Press.

Macías, Carlos. 2007. "La composición en anillo y la circularidad como recurso narrativo». En Homo ludens. Homenaje a Mario Vargas Llosa, coord. Guadalupe Fernández Ariza. Málaga: Ayuntamiento de Málaga, 21-47.

Martín, José Luis. 1974. La narrativa de Vargas Llosa: acercamiento estilístico. Madrid: Gredos.

Oviedo, José Miguel. 1981. Mario Vargas Llosa. Madrid: Taurus.

—. 2012. «La primera novela de Vargas Llosa». En M. Vargas Llosa. La ciudad y los perros. Edición conmemorativa del cincuentenario. Italia: Alfaguara, Real Academia Española, XXXI-LIX.

Páez, Enrique. 2001. Escribir. Manual de técnicas narrativas. Madrid: Ediciones SM.

Perniola, Mario. 2008. Del sentir. Traducción de César Palma. Valencia: Pre-Textos.

Ricoeur, Paul. 1996. Tiempo y narración. El tiempo narrado. Tomo III. Madrid: Siglo Veintiuno Editores.

Schwalb, Carlos. 2001. La narrativa totalizadora de José María Arguedas, Julio Ramón Ribeyro y Mario Vargas Llosa. Nueva York: Peter Lang.

Shaw, Donald. 1999. Nueva narrativa hispanoamericana. Boom. Posboom. Posmodernismo. 6. ${ }^{\mathrm{a}}$ ed. Madrid: Cátedra.

Sobrevilla, David. 2011. "Las concepciones novelísticas de Mario Vargas Llosa». En Mario Vargas Llosa y la crítica peruana, ed. Miguel Ángel Rodríguez Rea. Lima: Universidad Ricardo Palma, Editorial Universitaria, 401-457.

Sommers, Joseph. 1975. «Literatura e ideología: la evaluación novelística del militarismo en Vargas Llosa». Hispamérica, 4: 83-117.

Tenorio, Néstor. 2011. Mario Vargas Llosa. El fuego de la literatura. Lima: Arteidea Editores.

Vargas Llosa, Mario. 2012 [1963]. La ciudad y los perros. Edición conmemorativa del cincuentenario. Italia: Alfaguara, Real Academia Española. 